\title{
Antibiotic Awareness Week: An Update
}

It gives me immense pleasure to write this editorial for the International Healthcare Research Journal (IHRJ). IHRJ, in the past eight months, has grown from pillar to pillar and is gradually making its mark in the International Research Scenario.

The World Health Organization (WHO) has advised people to start planning in advance for the "World Antibiotic Awareness Week" which shall be observed from $13^{\text {th }}$ to $19^{\text {th }}$ November 2017 with the theme: "Seek advice from a qualified healthcare professional before taking antibiotics"

Considered one of the greatest global threats, Antimicrobial resistance (AMR) is gaining rapid attention of healthcare researchers worldwide. Global estimates put that $3.7 \%$ of new cases and $20 \%$ of previously treated cases of tuberculosis are caused by strains that are resistant to isoniazid and rifampicin, which proved to be effective previously. ${ }^{1}$ Antibiotic resistance was predominantly seen as a clinical problem in tertiary hospital settings, but recently, it has been detected in primary care centres also. According to $\mathrm{WHO}$, this phenomenon is found in all parts of the world. ${ }^{1}$

AMR associated diseases include tuberculosis, gonorrhoea (specifically Neisseria gonorrhoeae), typhoid fever and Group B streptococcus. ${ }^{2}$ It is also seen that most of the antibiotics used in medicine are usually prescribed by General Practitioners (GP).

The irrational use of antibiotic use is a major cause of AMR. The global estimates of the year 2010 state that India was the world's largest consumer of antibiotics for human health at $12.9 \times 109$ units (10.7 units per person) followed by China at 10.0 x109 units $(7.5$ units per person) and US at 6.8 x109 units (22.0 units per person) ${ }^{3}$
To combat the issue of AMR's, the Sixtyeighth World Health Assembly (WHA) in May 2015 took cognizance of this crisis and adopted the global action plan on AMR (GAPAMR), which outlined five strategic objectives: 4

1. Improve awareness and understanding of AMR through effective communication, education and training

2. Strengthen the knowledge and evidence base through surveillance and research 3. Reduce the incidence of infection through effective sanitation, hygiene and infection prevention measures

4. Optimize the use of antimicrobial medicines in human and animal health

5. Develop the economic case for sustainable investment that takes account of the needs of all countries and to increase investment in new medicines, diagnostic tools, vaccines and other interventions.

To tackle AMR, the need of the hour is antimicrobial stewardship and is advocated by the World Health Organization's Global Action Plan. India developed a National Action Plan on 19th April, 2017 to combat Antimicrobial Resistance, 5 the results of which, need to be closely monitored in the near future. However, combined efforts and strict monitoring from all nations is required to combat AMR that shall prevent its increasing incidence and reduce complications arising from it.

\section{REFERENCES}

1. World Health Organization (2014) WHO'S first global report on antibiotic resistance reveals serious, worldwide threat to public health.

2. Centers for Disease Control and Prevention (2012) Diseases/pathogens associated with antimicrobial resistance. 
3. Van Boeckel TP, Gandra S, Ashok A, Caudron Q, Grenfell BT, Levin SA, et al. Global antibiotic consumption 2000 to 2010: an analysis of national pharmaceutical sales data. Lancet Infect Dis. 2014;14(8):742-50. pmid:25022435.

4. World Health Organization. Global action plan on antimicrobial resistance. Geneva: World Health Organization; 2015.
5. Press Information Bureau, Government of India, Ministry of Health and Family Welfare. Available at http://pib.nic.in/newsite/PrintRelease.aspx ?relid $=161160$ [Last Accessed on $15^{\text {th }}$ October, 2017]

Cite this article as:

Thakar S. Antibiotic Awareness Week: An Update. Int Healthcare Res J 2017; 1(8):231-232.

Co-Editor, IHRJ and Senior Lecturer, Department of Public Health Dentistry, Swami Devi Dyal Hospital and Dental College, Panchkula, Haryana, India -134118 